\title{
Justicia socio-espacial y disputa por los espacios centrales en el barrio del Abasto (Buenos Aires)
}

Socio-spatial justice and dispute over the central spaces in the Abasto neighborhood (Buenos Aires).

Recibido: $30 / 07 / 2017$

Aprobado: 10/02/2018

Francisco José Cuberos-Gallardo ${ }^{1}$

Ibán Díaz-Parra²

\section{Resumen:}

El Abasto supone un caso ejemplar de disputa por la centralidad en Buenos Aires, en el que se superponen los proyectos de recualificación urbana orientados al consumo de clase media y al turismo con la ocupación de viviendas por inmigrantes pobres. Esta situación invita a examinar las distintas concepciones de justicia socio-espacial en conflicto, para lo que se instrumentalizan el concepto de economía moral utilizado por H. P. Thompson y James Scott y la concepción del espacio social popularizada por Henri Lefebvre y David Harvey. La exposición del caso se fundamenta en la combinación de una contextualización de los procesos urbanísticos y sociales desarrollados en el sector con una etnografía que sigue el caso de un edificio de vecinos ocupado por inmigrantes. El trabajo concluye advirtiendo sobre el riesgo de despolitización de una exaltación acrítica de las resistencias cotidianas cuando carecen de una dimensión pública.

\section{Palabras Clave:}

justicia socio-espacial, economía moral, gentrificación

\begin{abstract}
:
The Abasto is an exemplary case of dispute over the centrality in Buenos Aires, in which the projects of urban renewal aimed at the consumption of middle class and at the tourism overlap the occupation of houses by poor immigrants. This situation invites us to examine the different concepts of socio-spatial justice in conflict, using the concept of moral economy by $\mathrm{H}$. P. Thompson and James Scott and the conception of social space popularized by Henri Lefebvre and David Harvey. The presentation of the case is based on the combination of a contextualization of urban and social processes developed in the sector with an ethnography that follows the case of a building occupied by immigrants. The paper concludes by warning of the risk of depoliticisation of an uncritical exaltation of daily resistance when they lack a public dimension.
\end{abstract}

\section{Key words:}

Socio-Spatial Justice, Moral Economy, Gentrification

\footnotetext{
${ }^{1}$ Nacionalidad: español. Doctor en antropología social. Adscripción: Centro de Investigação e Estudos de Sociologia - Instituto Universitário de Lisboa (CIES-IUL), Portugal. francisco.jose.cuberos@iscte-iul.pt

${ }^{2}$ Nacionalidad: español. Doctor en geografía. .Adscripción: investigador en el Departamento de Geografía Humana de la Universidad de Sevilla, España: ibandipar@gmail.com
} 


\section{INTRODUCCIÓN}

Frente a la marcha triunfal del modelo neoliberal en la producción de ciudad en la mayor parte del mundo, en muchas de las grandes ciudades latinoamericanas estos patrones han encontrado fuertes obstáculos, bien por las dificultades dadas por la falta de desarrollo de los mercados de suelo y crédito, bien por la resistencia o simple presencia de unas clases populares vigorosas, ancladas en los espacios centrales desde hace décadas (Díaz Parra, 2014). Más allá de esto, varios países de América Latina han podido erigirse como excepciones, al menos parciales, a los planteamientos dominantes respecto de la construcción de la ciudad y a lo que es justo o injusto en este tipo de procesos. El caso de Argentina es especialmente significativo, en la medida en que su entrada en el siglo XXI estuvo marcada por una terrible crisis que convirtió este estado en el paradigma del fracaso de las políticas neoliberales de la década de los años noventa. En su capital, a pesar de llevar ya casi una década con un gobierno declaradamente neoliberal, el peso de las fuerzas contestatarias no ha dejado de ser notable, por la herencia de victorias pasadas, por la vitalidad de los movimientos urbanos y por el contrapeso que otros niveles de la administración del Estado han podido ejercer en determinados momentos.

El caso del Abasto puede ser ilustrativo de lo anterior. La zona que hoy se conoce con ese nombre, en su periodo de mayor abandono en los ochenta, se convirtió en el hogar de una importante población inmigrante y, en general, de estratos populares que en muchos casos ocuparon los degradados y abandonados edificios de la zona. Al mismo tiempo, tratándose de un enclave de gran valor simbólico de la ciudad, tanto por el emblemático edificio del mercado de Abastos como por su vinculación al tango y a la figura de Carlos Gardel, en los años noventa fue el objeto de un proyecto de renovación impulsado por la empresa inmobiliaria Inversiones y Representaciones Sociedad Anónima (IRSA S.A.) y respaldado por el magnate George Soros. El proceso de reurbanización, apoyado por el gobierno de la ciudad, absorbió un ingente flujo de recursos. La operación implicó en su momento inversión inmobiliaria, dinamización cultural y desplazamiento de ocupantes de bajos ingresos a cambio de compensaciones económicas. No obstante, lejos de implicar una simple y llana sustitución de población, la superposición de procesos ha implicado una disputa por la apropiación del enclave por grupos con intereses diversos y con diferentes formas de legitimarlos. De un lado, la renovación del área implica la restitución de los mecanismos de mercado y el disciplinamiento de los comportamientos, transformando el tugurio en enclave de consumo y ocio y restituyendo la justicia de la propiedad y la disciplina cívica. Del otro lado, la población de bajos recursos, viviendo en situaciones legales cuestionables y progresivamente desplazados por el mercado, reivindica su derecho al arraigo como habitantes originales, intentando permanecer en la ubicación excepcional que tiene el barrio y que les permite acceso a los recursos que proporciona la ciudad central.

En este trabajo aportamos una descripción de las transformaciones urbanísticas y sociales acontecidas en el Abasto para, a partir de ellas, reflexionar sobre las diferentes concepciones de la justicia y sus prácticas socio-espaciales asociadas. ¿Qué concepciones de la justicia socio-espacial implican las distintas prácticas espaciales mediante las que se crea y vive la ciudad? ¿Qué implicaciones en este sentido podemos encontrar en los espacios centrales inmersos en procesos de transformación social y urbanística? De partida, podríamos oponer, por un lado, las prácticas y 
concepciones que emanan de la propiedad privada, la libertad del consumidor y la disciplina cívica y, por otro, las de una economía moral que prima los valores de uso sobre el carácter progresivamente mercantil del espacio urbano. Ambas perspectivas se enfrentan en la recualificación de los espacios centrales, legitimando intereses opuestos en torno al uso de enclaves especialmente demandados.

El presente texto surge de la discusión de estas cuestiones a partir de un trabajo que combina, por un lado, una etnografía de corte antropológico desarrollada entre junio y septiembre de 2016, que implicó un período de observación participante con algunas de las comunidades de inmigrantes que viven en el porteño barrio del Abasto. Por otro lado, un análisis de la reestructuración social y urbanística del sector, típicamente geográfico, que parte de la reconstrucción del proceso histórico a partir de fuentes secundarias, revisión de documentos y análisis de los censos de población y vivienda. La combinación de ambas perspectivas en una antropogeografía permite articular la aportación de contexto y problemas típicos de la geografía, con la exploración de los significados que son concedidos al espacio por sus habitantes que permite la etnografía.

\section{Justicia socioespacial y economía moral}

Una de las claves del giro que imprimen Lefebvre (1973) y Harvey (1977) a la cuestión urbana se encuentra en el planteamiento de que las formas espaciales no son simples contenedores de cosas, sino parte sustantiva de los procesos sociales, en tanto toda la actividad humana es espacial de uno u otro modo. En este sentido, la justicia socioespacial no implica simplemente la dimensión espacial de justicia, sino el espacio como parte constitutiva de cualquier interpretación de la justicia.
Desde esta perspectiva de la producción del espacio, éste sería una construcción social en el que distintas culturas tienen diferentes formas de vivir su entorno y toman rasgos particulares de su mundo material para construir su concepción del mismo. Una construcción que no es individual, sino que se impone a todos los individuos, y que se encuentra vinculada a las estructuras de poder y a las relaciones sociales imperantes, modos de producción y de consumo (Harvey, 1996 y Lefebvre, 2013). En este sentido, una determinada concepción del espacio y del tiempo serían parte fundamental de la ideología dominante, entendida como conjunto de valores $y$ creencias que permiten la reproducción del sistema capitalista $\mathrm{y}$ hacen inconcebibles otras formas de sociabilidad (Larraín, 2007 y Zizek, 2011). La visión del espacio impuesta por el capitalismo sería una marcada por el carácter necesariamente efímero de toda configuración espacial, dispuesto a ser destruido creativamente por la innovación y por nuevas rondas de inversión. No obstante, al mismo tiempo, una concepción dominante del espacio y el tiempo es siempre disputada. Dentro de una sociedad existen distintas formas de entender el espacio que pueden entrar en conflicto. El conflicto entre distintos tipos de capital, entre capital y trabajo, entre grupos étnicos, el conflicto de género o en torno a la problematización de la relación con el medio por agrupaciones ecologistas, pueden implicar disputas respecto de las formas de concebir y habitar el espacio (Harvey, 1996). Por ejemplo, la gente desafía constantemente la concepción y articulación dominante (capitalista) del espacio cuando se resiste a los proyectos de renovación o cuando ocupa territorios allí donde no le corresponde por su posición en el mercado.

Igual que no existe una concepción del espacio que esté más allá de las prácticas espaciales dominantes en un determinado lugar y un determinado tiempo, tampoco 
existe una concepción neutral o ahistórica de justicia o de moral. Las concepciones de justicia o moral son igualmente ideológicas (Harvey, 1977). Por ello cabría preguntarse: ¿Qué concepción de la justicia socioespacial emana de la ideología dominante? ¿Qué prácticas sociales existen detrás de ellas? Por un lado, la institucionalidad liberal ofrece un marco, no único, pero si actualmente dominante para la acumulación capitalista, donde el derecho de propiedad, que implica monopolio sobre el espacio, y la libertad aparente de los agentes mercantiles, que permite su constante transformación y recreación en función de las necesidades de la acumulación, suponen el principal criterio de justicia. La ideología dominante plantearía el mercado como lugar de la justicia entre individuos iguales en derechos y libres, al tiempo que oculta la injusticia y la falta de libertad real de la explotación y la desigualdad (Larraín 2007). En términos espaciales, existiría una apariencia de libertad a la hora de elegir la ubicación y la relación de los individuos con el espacio, que oculta la segregación socio-espacial y la desigual distribución de recursos, servicios, etcétera. En este sentido, no es difícil demostrar cómo el poder de los individuos sobre el espacio mercantilizado, a la hora de elegir dónde van a vivir o como se relacionan con los distintos lugares, responde directamente de su posición social (Harvey, 1977). Frente a esto, la ideología liberal legitima el acceso desigual a la propiedad y al mercado afirmando el predominio del mérito como factor de acceso a una determinada posición de clase. El modelo del filantrocapitalista sería el paradigma de este discurso, cuya riqueza se legitima por su capacidad intelectual, sagacidad, moderación política y predisposición a gastar parte de su fortuna en buenas causas (Zizek, 2008). De esta forma, la decisión de renovar una pieza de la ciudad puede ser planteada como incluso como un acto de suprema justicia y restitución para el conjunto de la ciudad por el mecenas capitalista (Díaz Parra, 2016).

¿Existe en la práctica una concepción de la justicia socioespacial alternativa a aquella de la ideología dominante? Incluso en marcos donde funciona de manera relativamente estable la legalidad capitalista, se desarrollan prácticas espaciales alternativas que ponen en cuestión estos planteamientos. En términos generales, los grupos más desfavorecidos tienden a subvertir constantemente la legalidad liberal, traspasando fronteras, realizando pequeños hurtos, sabotajes, etcétera, lo que implica una concepción de la justicia espacial radicalmente diferente. La legitimación de estas prácticas se tiende a producir dentro de una visión de la economía moral. Scott rescata el concepto de economía moral inspirándose en el trabajo de E. P. Thompson. Este último, en su trabajo sobre el surgimiento de la clase obrera en Inglaterra, señala la existencia de unos principios morales tradicionales de justicia, basados en la reciprocidad, el don y/o la redistribución de recursos entre clases sociales, que se hacen incompatibles con los principios del libre mercado que se implantan con la consolidación del capitalismo, en la medida en que este modo de producción reduciría las reciprocidades humanas al nexo salarial (Thompson, 2012). Scott (2003) aplica el concepto de la economía moral a las revueltas campesinas del sureste asiático. Ciertos tipos de redistribución legitimarían las situaciones de desigualdad, pero la superación de ciertos límites daría argumentos a la economía moral para legitimar acciones de desobediencia. Scott habla de "formas de resistencia cotidiana" que identifica como manifestaciones de insubordinación sin protesta explícita, en situaciones de aparente paz social y conformidad de las clases desfavorecidas, que suponen formas de luchar contra la 
ideología hegemónica. Estas ideas son actualizadas en cierta medida por la búsqueda de grietas en el capitalismo de Holloway (2011) a través de prácticas que pueden ser espontáneas y no organizadas. Las ideas de Scott resultan compatibles con la feroz crítica a la ordenación estatal y los planteamientos autogestionarios de Lefebvre. En este autor se encuentra el que podría ser el planteamiento alternativo de justicia socio-espacial más difundido actualmente, aquél que implica el lema del derecho a la ciudad. Éste sería un derecho colectivo que implica el acceso al espacio y a los recursos de la ciudad, y más allá de esto, el derecho a la construcción y la reconstrucción de la propia ciudad, es decir, a una producción no alienada de la ciudad (Lefebvre, 1968).

Las críticas a la propuesta de Scott han señalado la necesidad de diferenciar estrategias dirigidas a mejorar aspectos parciales de la vida de los sujetos de aquellas que buscan cambios sociales de mayor alcance, así como el riesgo de ignorar otros tipos de acción social organizada y de protesta explícita. También se ha planteado que la focalización en estas resistencias cotidianas y el rechazo a los modelos de desarrollo estatal de Scott puede implicar cierto conformismo e incluso suponen una visión próxima a los planteamientos neoliberales más extremos (Roca, 2017). La necesidad de ciertos niveles de centralización e institucionalidad para propiciar procesos de redistribución espacial ya ha sido argumentada por Harvey (2013, p. 111) frente a las posiciones libertarias.

\section{La renovación del abasto}

El barrio de El Abasto toma su denominación del colosalista edificio de estilo art decó donde se localizaba el antiguo mercado (de abasto) de Buenos Aires, en una localización progresivamente central como consecuencia de la expansión de la ciudad. Ubicado entre los distritos de Almagro y Balvanera se encuentra dentro del área de influencia del centro comercial tradicional de la ciudad (Once, dentro de la comuna de Balvanera) (ver figura 1).

\section{FIGURA 1. PLANO DE LOCALIZACIÓN DE EL} ABASTO

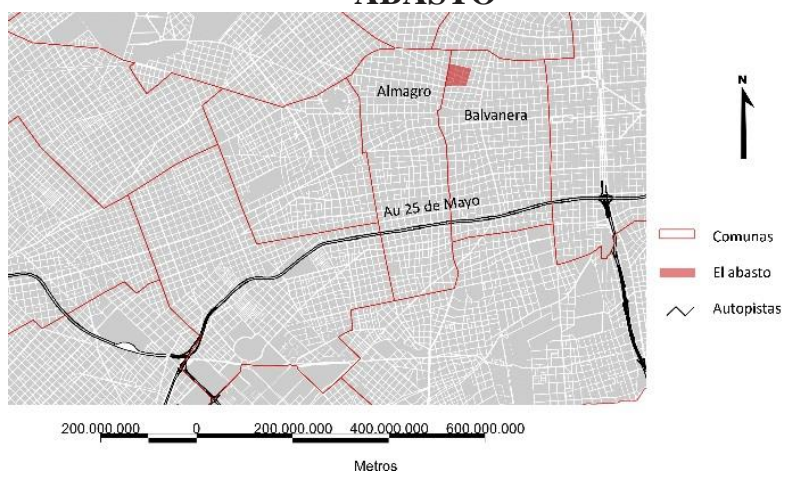

Fuente: Elaboración propia.

La operación de El Abasto en el marco de la reestructuración de la pobreza urbana de Buenos Aires

El entorno del edificio de El Abasto se habría configurado en su apogeo como un ambiente popular, de inmigrantes europeos, vinculado a la cultura del tango, con algunos de los locales antiguos más representativos de esta música e incluso con la que fue residencia de Carlos Gardel. La progresiva degradación del edificio del mercado (junto con su entorno), condujeron a su cierre en 1984. A partir de este momento el sector sufrió un profundo declive, proliferando las ocupaciones irregulares de edificios y las viviendas colectivas en alquiler para una población muy pobre y con un importante componente de inmigración extranjera. A principios de los noventa, en pocas cuadras había más de medio centenar de casas tomadas.

Esta cuestión tiene mucho que ver con los cambios urbanísticos que había estado sufriendo la ciudad hasta ese momento. La dictadura militar había fomentado el desplazamiento de clases populares desde la ciudad central hacia su cono urbano mediante la destrucción de barrios degradados para el desarrollo de grandes 
estructuras viarias. En la década de los ochenta, con la transición a la democracia se habría producido el efecto contrario, con la entrada de clases populares a la ciudad a través de la densificación de los asentamientos informales preexistentes y la ocupación de instalaciones abandonadas en diversos enclaves centrales (Rodríguez, 2009). En la década siguiente, siguieron los cambios en la distribución geográfica de la pobreza urbana, en un contexto de elevado crecimiento de la misma. Si en 1994 la población local ubicada por debajo del umbral de la pobreza era del 6,7\%, en 2003 ésta alcanzará hasta al 21,7\% de la población. Este incremento se plasmó en la multiplicación de los asentamientos precarios (villas miseria), que pasaron de alojar 50.608 a 108.056 personas. No obstante, la ocupación de edificios experimentó una evolución inversa. Entre 1991 y 2001 la población con este tipo de relación irregular con la vivienda pasó de 160.000 (15,6\% de la población porteña) a $79.000(7,7 \%)$ (Carman, 2006, 61-63). Esto tiene que ver con un giro político hacia una menor tolerancia hacia este tipo de acciones, que implicó en la práctica la expulsión a la periferia de una población pobre cada vez más numerosa. La otra cara de este urbanismo neoliberal sería el desarrollo de ambiciosos programas de reestructuración urbana, cuyo máximo ejemplo sería la reestructuración de los viejos docks de la ciudad en una urbanización de lujo: Puerto Madero.

El proyecto de renovación de la zona del Abasto es simultáneo al desarrollo del Puerto Madero y sigue una lógica similar de recuperación de enclaves urbanos centrales e históricos. Tras varios proyectos truncados y negociaciones del gobierno local con distintos interesados, en 1994 el Mercado y dos manzanas aledañas fueron vendidos a la empresa IRSA, propiedad de George

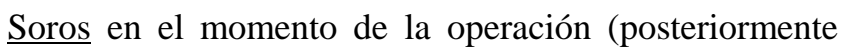

cambió de propietarios, justo antes de la crisis económica de 2000). Se da el caso de que Soros era el mayor terrateniente de Argentina y el más grande operador de bienes raíces en este momento, y como tal también intervino en la operación inmobiliaria de Puerto Madero. IRSA era y es una sociedad comercial dedicada a los bienes raíces, propietaria de los principales centros comerciales y responsable de algunos de los mayores proyectos inmobiliarios del país. En 1997 comenzaron las obras de rehabilitación que se materializaron en un gran centro comercial ocupando todo el edificio del mercado, un hipermercado en una parcela contigua y un complejo habitacional compuesto por tres torres de apartamentos dentro de una manzana cerrada y fuertemente vigilada. Asimismo, IRSA adquirió locales deteriorados en edificios que eran casas tomadas desde hacía lustros, varias de ellas antros tangueros legendarios de la historia local, apostados de cara al mercado. La actuación de IRSA pudo generar un efecto contagio sobre otros agentes privados, y durante el periodo de reestructuración del sector se abrió un hotel de cuatro estrellas y las agencias inmobiliarias comenzaron a trabajar intensamente en la zona. En este periodo se creó también la Fundación IRSA, orientada a la realización de actividades sociales y de formación, que desarrollaría el proyecto de Museo de los Niños en el Abasto. La operación implicó un elevado número de desalojos y demoliciones de casas tomadas que fueron organizados por la propia empresa. IRSA fue comprando los predios tomados, desalojando a los ocupantes a cambio de compensaciones económicas y, posteriormente, rehabilitándolos o vendiéndolos a otros promotores.

La rehabilitación del entorno construido se orientó tanto a nuevos residentes de estratos superiores como a la atracción de turistas, dentro de un proceso claro de 
tematización en torno a la cultura del Tango y al modernismo de la época de construcción del mercado. Esta tematización tiene su núcleo en la calle Carlos Gardel, peatonalizada en el año 2000, con varios restaurantes y una estatua del tanguero. En esta activación del valor patrimonial de la zona participaron activamente tanto la empresa de Soros, como el gobierno y asociaciones e iniciativas de los propios vecinos. Además, el Estado colaboró con una presencia policial permanente desde el inicio de las obras. Según comenta Carman (2006), que realizó un extenso trabajo de campo en el área, los habitantes de la zona confundían en ocasiones el liderazgo de la operación de renovación urbana, que no sabían si adjudicar a la empresa o al gobierno local, en la medida en que ambos aparecían frecuentemente en los medios reivindicándola. La intervención, con un fuerte impacto en la opinión pública, se vendió como un segundo Puerto Madero. De esta manera, el capital privado se erigió como salvador tanto del patrimonio cultural de la ciudad como de la economía local, contribuyendo con un nuevo polo turístico-cultural para atraer visitantes.

\section{El abasto en la actualidad: entre la gentrificación y la pobreza urbana}

La reforma de El Abasto tiende a tomarse como un caso frustrado de gentrificación planificada. La enorme inversión privada, coordinada con la intervención pública, no tuvo el impacto inicial esperado a causa de la enorme crisis que sacudió el país entre 2000 y 2003. A pesar de todo, el barrio se ha renovado como enclave de ocio y consumo de la ciudad, ubicado estratégicamente junto al centro comercial de la ciudad y colindante a barrios pudientes de clase media porteña. Las transformaciones urbanísticas acontecidas durante las últimas dos décadas se plasman en primer lugar en la presencia de nuevos elementos arquitectónicos, claramente orientados a sectores socioeconómicos de clase media y media-alta, entre los que destacan las Torres Abasto - complejo habitacional de lujo, cerrado y video-vigilado- y el centro comercial Shopping Abasto, emplazado en el antiguo mercado, pero estética y funcionalmente renovado. Paralelamente, pequeños edificios originalmente usados como casas de vecinos fueron reconfigurados como restaurantes, tiendas de souvenirs y otras formas comerciales orientadas en gran medida al turismo. Estos nuevos usos del espacio, lejos de constituir iniciativas aisladas, están conectados a través de un hilo discursivo que redefine el Abasto como un territorio de alto valor patrimonial. El rescate de un relato edulcorado sobre la historia del barrio, fuertemente ligada a la del tango, se afirma recurrentemente en forma de estatuas, carteles y todo tipo de referencias a Carlos Gardel. La rehabilitación de la propia casa de Gardel como museo temático, la presencia constante de la imagen del artista o la adjudicación de su nombre a elementos como calles, plazas y hasta una estación de metro han contribuido a reforzar la imagen castiza. Incluso las tres torres-country, símbolo arquitectónico por excelencia del nuevo Abasto, fueron bautizadas con los muy tangueros nombres de Carlos Gardel, Enrique Santos Discépolo y Aníbal Troilo. En la última década, además, se ha ido forjando una red de pequeñas salas de teatro, cafés-teatro y galerías de arte, suponiendo un importante factor de atracción para un usuario del espacio joven, formado y bohemio (ver figura 2). 


\section{FIGURA 2. ESTABLECIMIENTOS CULTURALES EN EL ABASTO.}

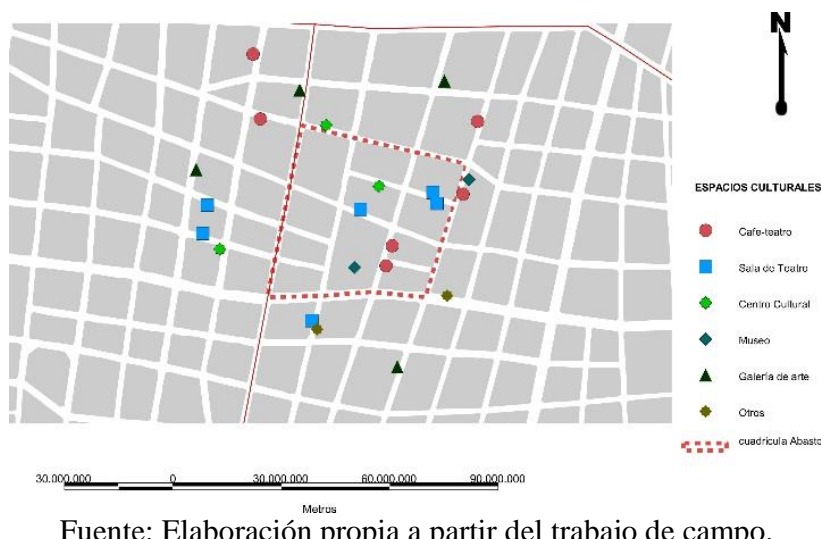

Los condominios de clase media han ocupado toda la peatonal de Carlos Gardel, con la única excepción de un viejo conventillo que muestra pintadas contra un posible desalojo en su fachada. Sin embargo, la mayor parte de las nuevas construcciones se han ubicado a la sombra de las tres torres country, donde las típicas operaciones en parcela se complementan con bares y boliches para un público joven y generalmente alternativo. Aunque la presencia de población joven y de clase media es notoria, los datos del censo no reflejaban una gentrificación contundente, lo que puede venir justificado por el limitado rango temporal que abarcan. En la figura 3, donde se representa un indicador fuertemente correlacionado con el estatus social como la proporción de población con estudios universitarios, se observa claramente la ubicación del sector en la frontera entre el norte rico de la ciudad y el sur más pobre. Entre 2001 y 2010 se constata una consolidación del entorno en valores altos para el indicador, especialmente al norte y al oeste del centro comercial, mientras que en las manzanas adyacentes, más identificadas con la toponimia de El Abasto, se conservan unos valores relativamente bajos, más propios del sector sur de la ciudad, de tal forma que en el periodo intercensal la zona ha quedado como una pequeña isla de valores bajos rodeada de sectores más o menos privilegiados de la ciudad (ver figura 3 )

\section{FIGURA 3. PROPORCIÓN DE UNIVERSITARIOS 2001-2010}

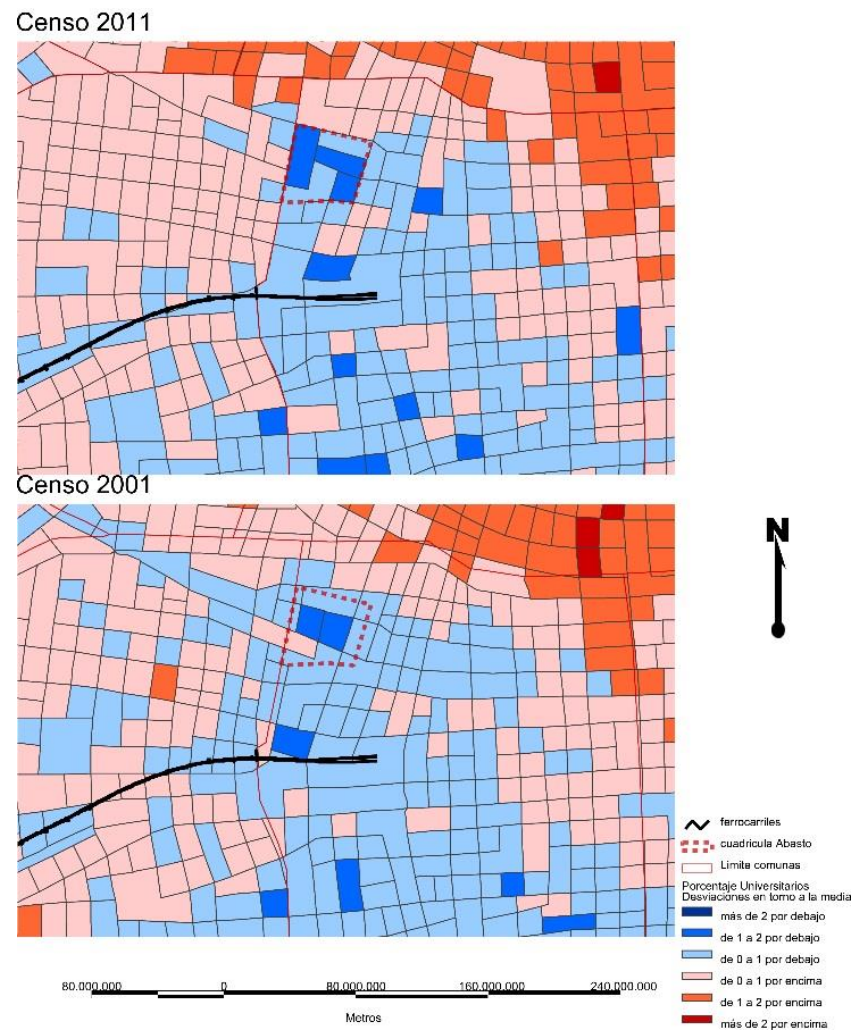

Fuente: Elaboración propia a partir de los Censos de Población y Vivienda 2001 y 2010.

El entorno inmediato del Abasto, las cuadras inmediatamente al norte y al este, siguen formando parte del importante clúster de población inmigrante extranjera que se extiende desde el barrio de Once (Comuna Balvanera), con su epicentro en la plaza Miserere, y sigue habiendo constancia de precariedad habitacional en cuanto a la existencia de hogares sin suministro de agua y cierto grado de hacinamiento por la subsistencia de los conventillos. Los datos del cuadro 1 comparan el Abasto con las dos comunas entre las cuales se encuentra situado y con los datos para el conjunto de la ciudad. En términos generales para 2010, el sector seguía estando muy por debajo de la ciudad e incluso bastante por debajo de la 
comuna Balvanera para indicadores sociales como el porcentaje de universitarios o el porcentaje de hogares con computadora. Así mismo, la cuadrícula del Abasto se muestra como un sector caracterizado por un envejecimiento mucho menor que el del resto de la ciudad y de las zonas adyacentes, y por acoger una gran cantidad de población nacida en el extranjero, cercana al $30 \%$. Mientras que la ocupación, el analfabetismo y el hacinamiento se encuentran ligeramente por encima de la de los distritos circundantes.

\section{CUADRO 1. INDICADORES SOCIODEMOGRÁFICOS} 2010

\begin{tabular}{|c|c|c|c|c|}
\hline & $\begin{array}{r}\text { El } \\
\text { Abasto }\end{array}$ & $\begin{array}{c}\text { Alm } \\
\text { agro } \\
\text { (Comuna } \\
\text { ) }\end{array}$ & $\begin{array}{c}\text { Balva } \\
\text { nera } \\
\text { (Comuna) }\end{array}$ & $\begin{array}{r}\text { Bue } \\
\text { nos Aires }\end{array}$ \\
\hline $\begin{array}{l}\text { Población } \\
\text { total }\end{array}$ & $92^{34}$ & $\begin{array}{l}1790 \\
05\end{array}$ & $\begin{array}{l}18753 \\
7\end{array}$ & $\begin{array}{c}2890 \\
151\end{array}$ \\
\hline $\begin{array}{l}\text { \%Universi } \\
\text { tarios }\end{array}$ & $.11^{17}$ & 30.14 & 26.45 & $6^{29.4}$ \\
\hline $\begin{array}{c}\text { \%Hogares } \\
\text { con } \\
\text { computadora }\end{array}$ & $\begin{array}{l}67 \\
.05\end{array}$ & 76.45 & 72.91 & $5^{74.6}$ \\
\hline $\begin{array}{l}\text { \%Mayores } \\
\text { de } 65\end{array}$ & $.06^{12}$ & 17.18 & 16.17 & $8^{16.8}$ \\
\hline $\begin{array}{l}\text { \% Nacidos } \\
\text { en el } \\
\text { extranjero }\end{array}$ & $.82^{27}$ & 10.81 & 16.33 & $3^{12.5}$ \\
\hline $\begin{array}{l}\text { Promedio } \\
\text { personas por } \\
\text { vivienda }\end{array}$ & $55^{2 .}$ & 2.43 & 2.44 & 2.66 \\
\hline $\begin{array}{l}\text { \%Desocup } \\
\text { ados }\end{array}$ & $5^{4 .}$ & 3.99 & 4.28 & 4.25 \\
\hline $\begin{array}{l}\text { \%Analfab } \\
\text { etos }\end{array}$ & $53^{0 .}$ & 0.38 & 0.43 & 0.46 \\
\hline $\begin{array}{l}\text { \%Hogares } \\
\text { sin agua }\end{array}$ & $5^{0 .}$ & 0.3 & 0.6 & 0.5 \\
\hline
\end{tabular}

\begin{tabular}{|c|c|c|c|c|}
\hline $\begin{array}{c}\text { \%Viviend } \\
\text { as ocupadas }\end{array}$ & .85 & 74.8 & 75.36 & 57.4 \\
& & & & 5 \\
\hline
\end{tabular}

Fuente: Elaboración propia a partir de los Censos de Población y Vivienda 2010.

\section{Economía moral y resistencia a la gentrificación en el abasto}

Todo el proceso de redefinición espacial en torno al Abasto ha impulsado paralelamente la consolidación de un discurso que codifica crecientemente las formas correctas de habitar el barrio. Prueba de ello son el aumento de la presencia policial y la emergencia de un discurso de amplio eco en los medios de comunicación que estigmatiza determinados usos del espacio observables en el Abasto y urge a actuar contra ellos. Los boliches de la zona, discotecas orientadas a población inmigrante de origen latinoamericano, aparecen caracterizados como lugares vinculados al hurto, al consumo de sustancias prohibidas y a la violencia. La venta ambulante, igualmente asociada a población inmigrante de otros países latinoamericanos, de África o incluso del interior del país, es crecientemente visibilizada como ejemplo de mala práctica. Y muy especialmente los inquilinos irregulares, presentados generalmente como pobres, inmigrantes y conflictivos, son construidos como problema y como amenaza al valor potencial del barrio. Dentro de las que se consideran malas prácticas espaciales, el ocupante de vivienda aparece como el enemigo por excelencia por violar triplemente los valores propugnados por los impulsores del proceso de renovación: atenta contra el principio de propiedad -al ocupar ilegalmente suelo urbano-; contra el principio patrimonial -al ocupar suelo de especial valor histórico para la ciudad-; y contra el principio de nacionalidad -al ocupar suelo argentino y ser equiparada generalmente la figura del ocupa a la del inmigrante-. Esta triple violación, afirma Carman, supera el principio 
de "máxima intrusión socialmente aceptable" (Carman, 2006), y legitima automáticamente la puesta en marcha de mecanismos de restitución de la justicia. No es de extrañar así que el Abasto haya sido escenario de desalojos pedagógicos: intervenciones explícitas de la autoridad contra los ocupantes que son visibilizadas a amplia escala en el afán de disciplinar a la población en los usos del territorio definidos como correctos y castigar públicamente a quien no los respeta.

El proceso de recualificación urbana del Abasto no sólo ha tenido un efecto material en el paisaje de este céntrico sector de Buenos Aires, sino que ha venido acompañado de toda una redefinición discursiva de la identidad del barrio y de quiénes deben formar parte de él. Una tendencia que a su vez trasciende los límites del barrio, y que conecta con un nuevo modelo de ciudad claramente anclado en los principios neoliberales.

El Abasto constituye en este punto un escenario de observación privilegiado. En este barrio central el proceso de renovación urbana va a ajustarse de forma estricta a un discurso neo-higienista, que preconiza la recuperación las zonas céntricas, históricas o genéricamente valiosas de la ciudad al tiempo que reserva la periferia - la provincia o el cono urbano- como espacio natural para la población de menos recursos. La población más humilde del barrio no es ajena a esta tendencia, y con frecuencia ilustra todo este proceso como una fuerza de empuje que trata de expulsarles a las villas miseria, que a su vez son percibidas como lugares peligrosos:

“[A mí] no me gustaría ir a la villa, porque no es vida para un chico. No es porque los margine, pero yo no estaría tranquila salir a buscar trabajo y dejarlos allá a los chicos. Porque tú sabes que en una villa, o en cualquier asentamiento que haiga, siempre rigen o las peleas o los balazos. O saber si tú vas a volver en la madrugada bien de tu trabajo y encontrar bien a tus hijos. Acá los chicos pueden salir, jugar, los miramos, los llevamos al parque". (Violeta, 43 años, peruana)

Por contraste con la villa, el barrio del Abasto aparece muy valorado en el discurso de la población del barrio más afectada por el proceso de renovación. Frente al ambiente peligroso y lejano que representa la villa, este barrio es construido como un lugar valioso por su centralidad, clave para el acceso al empleo, y por su tranquilidad. Estos vecinos, generalmente alojados en conventillos mediante el pago de rentas compartidas o bien por ocupación ilegal, expresan un alto apego hacia el barrio, y reflejan en sus palabras una clara conciencia del valor de este territorio.

"Lo que más me gusta del barrio es que tengo todo accesible: para comprar, para los chicos... tengo la placita, puedo tomarme un mate con mis hijos, conversar... es lo que más me agrada del barrio, que es tranquilo". (Violeta, 43 años, peruana)

"No, es que para nosotros es muy importante estar acá. Porque mire que los chicos van todos a las escuelas de acá. Una está ahí a unas cuadras y la otra acá detrás. Y esas de primaria, la de secundaria está para el otro lado pero está cerca igual. Entonces ellos andan siempre moviéndose acá. Y la mayoría de los adultos igual trabajamos por acá. Entonces si nos vamos 
a provincia ¿dónde trabajamos?" (Pamela, 33 años, argentina)

Para estos moradores, el proceso de recualificación urbana del Abasto implica un riesgo real de expulsión a la periferia, que es construida a su vez como un espacio inseguro e indeseable. No es de extrañar por tanto que, para estos sectores poblacionales, la regeneración urbanística del barrio sea experimentada fundamentalmente como un acto de injusticia. Así, y distanciándose de manera evidente del discurso gentrificador que focaliza el conflicto en los boliches, los vendedores ambulantes y los ocupantes ilegales, encontramos con frecuencia discursos que localizan con claridad meridiana los intereses de clase que hay detrás de la recuperación urbana del Abasto, y que los identifican como esencialmente enfrentados a los suyos.

"El problema es que los ricos compran las casas pero las dejan vacías. Porque yo no puedo pagar 20.000 pesos por una casa si mi marido gana 10.000. Pero a ellos les dan igual los pobres, porque ellos son ricos y sólo les importa la gente que tiene guita (...) Ahora los ricos quieren quedarse con la capital. Quieren quedarse con los terrenos de aquí y hacer dinero, y que los pobres nos vayamos a provincia. Los ricos a la capital y los pobres a provincia”. (Pamela, 33 años, argentina)

“Ésa es la parte mala. En la ciudad pasa eso: que la gente rica se está apropiando de todo en la ciudad. Y destruyen a la gente de menos recursos. "Que se vayan a provincia". Si no pueden pagar un alquiler, entonces que se vayan a provincia. ¡El país

es grande!’. (Ángela, 37 años, peruana)

Nos encontramos así ante una población que interpreta el proceso de recualificación urbanística del Abasto como un acto de injusticia, y que lo enfrenta a través de un discurso alternativo sobre la justicia socioespacial que debe regir la ordenación del territorio. Este discurso va a caracterizarse fundamentalmente por una reivindicación de su propia dignidad en términos de clase -como trabajadores- o directamente como seres humanos; así como por una priorización del valor de uso del suelo urbano frente a su valor de cambio en tanto mercancía dentro del mercado capitalista.

"Ahora ellos dicen: esto es una propiedad privada, por eso no nos podemos meter. (...) pero como dicen: hay un derecho a la vivienda. $\mathrm{Y}$ ése tiene que superar el derecho del dueño, que tanto tiempo no se preocupó también por el terreno. Ojalá se priorice ese derecho a la vivienda acá". (Ángela, 37 años, peruana)

Desde esta perspectiva, las recientes transformaciones acontecidas en el Abasto son interpretadas como una medida política, que al apostar por la especulación urbanística como fuente de negocio genera necesariamente una violación del derecho fundamental de las personas a vivir dignamente. Los impulsores de esta apuesta suelen ser identificados genéricamente como "los ricos", una etiqueta que engloba tanto a los inversores privados que se benefician con la compra y venta de suelo como a las autoridades políticas que respaldan sus intereses y generan la estructura legal-institucional para canalizarlos. Frente a esta situación, los vecinos más afectados por la precariedad van a desarrollar sus propias 
estrategias de lucha por el acceso a la centralidad que representa el Abasto. Unas estrategias que, como veremos a continuación, suponen la plasmación espacial de todo un sentido alternativo de la justicia.

\section{Geografías de la vida cotidiana en un conventillo de El Abasto}

Para la exploración de estrategias de resistencia vecinal frente al proceso de gentrificación en el Abasto, así como el sentido de la justicia sociespacial que éstas reflejan, abordaremos un caso etnográfico analizado en profundidad durante nuestro trabajo de campo. Se trata de una comunidad vecinal compuesta por un total de veintisiete familias, que habitan una gran casa de vecinos construida según el modelo allí llamado casa chorizo. Este tipo de inmueble se ordena en torno a un patio interior alargado y en dos plantas, que da acceso a numerosas habitaciones. Además, a los cuartos originalmente incluidos se han ido añadiendo otros autoconstruidos por los vecinos en la parte alta del edificio, en lo que parece ser una práctica habitual en la zona. Cada una de estas habitaciones suele acoger a más de una persona, y con frecuencia a familias compuestas por varios miembros. Cada familia cocina en el interior de su cuarto, y existen tres baños de uso compartido para todos los residentes en el edificio.

De todas las familias que habitan la casa, sólo tres son argentinas, siendo el resto de origen peruano. Han ido llegando a la casa a lo largo de un período de tiempo dilatado, incluyendo familias que afirman llevar dieciocho años habitando el lugar. Hablamos por tanto de un proceso habitacional directamente ligado a la migración peruana que, aun teniendo raíces previas, experimenta un notable crecimiento a partir de la segunda mitad de los años noventa. Otra característica de esta corriente migratoria que es notable en la comunidad vecinal es su marcada feminización: la mayor parte de las familias están organizadas en torno a jefas de hogar, abundan las madres solteras y son mujeres en casi todos los casos las que inauguraron la cadena migratoria hacia Argentina.

Todos estos inquilinos relatan haber estado pagando rigurosamente una cuota de alquiler durante largo tiempo a un señor, también peruano, que estuvo habitando uno de los cuartos hasta comienzos de 2015. En estas fechas los vecinos reciben una primera amenaza de desalojo por parte de una abogada que dice representar a la familia propietaria del inmueble. Descubren entonces que el citado vecino que les cobraba no desempeña en realidad el papel de intermediario que se arroga, y que en la práctica está estafando al resto de los inquilinos. El señor es expulsado de la comunidad $\mathrm{y}$, desde ese momento, comienza una segunda etapa de ocupación "consciente" en que los vecinos van desarrollando un discurso que reivindica expresamente su derecho a continuar viviendo en esa casa.

A pesar de la precariedad física que impone el hecho de habitar habitaciones pequeñas, compartidas generalmente por varias personas, todos manifiestan un alto apego a la casa que ocupan, que debe ser interpretado en el marco de unas densas redes vecinales que asumen labores de gran importancia. Las mujeres, que son mayoría, juegan un papel especialmente activo en unas tareas de cuidado mutuo que incluyen el cuidado conjunto de los niños, la prestación ocasional de recursos y la organización colectiva de las tareas domésticas. Debe tenerse en cuenta que casi todas ellas se emplean en el servicio doméstico y en la hostelería, sectores afectados por horarios largos y cambiantes. En este contexto, disponer de un grupo amplio de vecinos supone una ventaja considerable a la 
hora de afrontar las obligaciones propias de la vida cotidiana.

Más allá de estas funciones de cuidado, las redes vecinales que estas familias han construido resultan fundamentales para el propio mantenimiento del inmueble. Tratándose de una vivienda antigua, y seriamente afectada por el abandono practicado por sus propietarios, la ocupación del inmueble ha exigido de los inquilinos una intervención constante para el arreglo de desperfectos y la acometida de mejoras.

"Nosotros la hemos ido arreglando. Todos los chicos ponían la mano. Todos los esposos, o los primos, los hermanos ponían la mano. Hasta las mujeres. Si teníamos que hacer limpieza general, todas las mujeres en el techo. Los hombres bajaban escombros, limpiábamos, limpiábamos los tanques. Por ejemplo, me decían: mira, que este cable ya no va, hay que cambiar de cables, hay que pintar, hay que arreglar el baño, hay que poner una puerta, que queda prolijo. Para vivir como la gente". (Violeta, 43 años, peruana)

El mismo grado de organización colectiva y solidaridad mutua se observa a la hora de afrontar los pagos derivados del consumo de servicios básicos. Los vecinos, que se han esforzado por pagar rigurosamente los recibos derivados del uso de luz y agua, reparten el gasto de manera equitativa, teniendo en cuenta el número de inquilinos de cada habitación, pero siendo también sensibles a las dificultades coyunturales que cada familia puede atravesar. En este sentido, a lo largo de los últimos años han tenido que hacer frente a gastos excepcionales derivados de estos pagos. Cuando esto sucede, las facturas pueden llegar a suponer importes que exceden la capacidad de pago de los vecinos. En estos casos, la solución aparece ligada a prácticas cooperativas de obtención de fondos, entre las que se incluye, por ejemplo, la pollada, una práctica importada de Perú y a la que los vecinos dicen haber recurrido en momentos de especial dificultad. La pollada consiste en la dedicación de unos fondos recabados entre los vecinos para la compra de carne de pollo que posteriormente es cocinada de forma colectiva y ofrecida al público a cambio de un importe que, a la postre, permite la entrada de un remanente que es incorporado al fondo vecinal y que hace posible acometer los pagos. Los invitados a la comida son amigos y conocidos, generalmente interpelados en tanto peruanos, que cooperan así a la superación de una dificultad económica excepcional en el marco de una jornada de convivencia con comida típica del país de origen.

"Para organizarnos hacemos una pollada entre los vecinos, y recaudamos dinero con eso. Porque esa comida solamente la hacemos para hacer una actividad, y para recaudar fondos. Prosalud, pro-casa, pro-esto o pro-cualquier cosa pero es apoyar, es una comida especial. (...) Si había que arreglar la casa, todos juntos. Esa reja, por ejemplo, la pusimos todos juntos, la reja de la puerta. Recaudábamos cada vecino, cuánto toca, entre todos poníamos. (...) Una vez nos vino veintitrés mil de un porrazo de luz. Y lo pagamos, haciendo la pollada lo pagamos. O sea, que nunca hemos dejado de pagar”. (Alma, 46 años, peruana) 
El despliegue de estas estrategias cooperativas ha resultado esencial tanto para evitar el deterioro del inmueble como para evitar cortes en el suministro de servicios básicos. Se trata, en definitiva, de formas solidarias de gestión de los recursos que hacen posible la resistencia frente a la presión de un proceso especulativo que determina un aumento sistemático de los costes. Hay que notar que, más allá de la subida del precio del suelo en el Abasto y del abandono de los inmuebles por parte muchos propietarios, el encarecimiento de los servicios también opera en este caso como un factor de presión sobre los vecinos. Este fenómeno ha llegado a adquirir una especial resonancia a raíz del llamado "tarifazo", una subida excepcional de los servicios básicos experimentada durante los dos últimos años y directamente derivada de las políticas liberalizadoras impulsadas por el gobierno de Mauricio Macri. Este ascenso de los precios en los servicios públicos, y muy especialmente en el sector energético y en el transporte público, ha sido especialmente notable en el agua y en la luz, produciéndose en este último servicio subidas de hasta un $1.600 \%$.

El tarifazo, sin embargo, no se ha reflejado en una mejoría en la prestación de estos suministros. Los cortes de luz fueron frecuentes durante el invierno de 2016, y de hecho van a ser determinantes en un episodio crucial para la vida de los vecinos de la calle Zelaya. A comienzos del mes de julio, y coincidiendo con un severo descenso de las temperaturas, dos cuadras de la zona van a quedar sin luz durante varios días. En este contexto una de las niñas residentes en la vivienda enciende una vela y provoca un incendio que afecta a la totalidad del inmueble y determina el desalojo de los inquilinos. Los vecinos afectados, que durante un año y medio han luchado judicialmente contra el inicio de un proceso de desalojo promovido por los propietarios del inmueble, se ven en la calle. A partir de esta nueva situación, podemos observar el despliegue de estrategias adicionales que, más allá de habilitar formas de resistencia a la precariedad, asumen una labor proactiva de visibilización de un sentido alternativo de la justicia socioespacial.

\section{La lucha por la vivienda tras el incendio}

Una vez producido el incendio, sobre las dos del mediodía, los inquilinos se apostan a la puerta del edificio con la esperanza de que los daños sean mínimos y se les permita el reingreso. Las dos primeras noches la mayor parte de ellos duerme al raso. A partir de la tercera, y ante el carácter confuso de las noticias y la presencia permanente de un vigilante de seguridad que impide el acceso a la casa, parte de las familias comienza a buscar alojamiento en casas de familiares y amigos. Otros, sin embargo, construyen un campamento improvisado que poco a poco se va poblando de carpas -tiendas de campaña-, que son conseguidas a través de vecinos solidarios y del apoyo que comienzan a recibir de Nuevo Encuentro, una organización política kirchnerista con una sede ubicada en la misma calle. En poco más de una semana, la calle Zelaya pasa a albergar un campamento bien perpetrado donde buena parte de las familias pernoctan, y donde todas confluyen durante las horas del día para supervisar las pertenencias, informarse sobre la evolución del problema y debatir en asambleas vespertinas las estrategias a seguir con el objetivo de recuperar la casa. Pronto consiguen la instalación por parte del gobierno de la ciudad de dos sanitarios portátiles junto a las carpas. Paralelamente, tanto Nuevo Encuentro como la organización revolucionaria La Brecha y la Coordinadora de Inquilinos de Buenos Aires (CIBA) comienzan a frecuentar el campamento, a participar en las 
asambleas y a apoyar a los vecinos en su estrategia de recuperación del edificio.

Dicha estrategia va a ser canalizada fundamentalmente a través de dos vías. De un lado, a nivel jurídico, los vecinos contratan a una abogada que tramitará sus demandas de reingreso y una denuncia a Edesur como responsable indirecta del incendio. También las organizaciones que apoyan pondrán a sus abogados a disposición de la causa. Por otra parte, los vecinos asumen que el logro de este objetivo dependerá en buena medida de una presión sobre las instituciones que, como veremos a continuación, plantea una intervención profunda sobre el espacio público y expresa de esta forma sentidos alternativos de la justicia socioespacial.

La propia consolidación del campamento en la calle Zelaya va a canalizar toda una serie de intervenciones sobre el espacio que visibilizan la cara menos conocida del abasto - la pobreza, la inmigración, la precariedad habitacional-, y la presentan como el producto de una injusticia política. El tráfico rodado queda cortado en la calle, y permanecerá así durante los dos meses en que hacemos seguimiento al caso. Sólo dos días después del incendio, varios vecinos colocan una gran pancarta a la entrada de la cortada en la que puede leerse "Zelaya $=27$ familias y 50 niños en la calle. Justicia ya". Durante las primeras semanas, además, las asambleas diarias congregan a un buen número de vecinos solidarios, así como a militantes de organizaciones políticas $y$ movimientos sociales, que llegan a superar el medio centenar y a presentar así una estampa claramente contrastiva con el carácter comercial y turístico de la zona. Todas estas intervenciones sobre el espacio logran que en muy poco tiempo la calle Zelaya, ubicada a un costado del Shopping Abasto y en pleno tráfico de turistas y paseantes locales, transmita un mensaje claramente impugnador del discurso que presenta el Abasto como un híbrido urbano de éxito económico y gloriosa tradición.

Mientras tanto, las redes tejidas entre los vecinos afectados son reforzadas y adecuadas a la especial dureza del momento. La vida en la calle obliga a extremar las labores de ayuda mutua y exacerba en los afectados un sentido de la solidaridad que contrasta con un sentimiento paralelo de abandono institucional. Comienza la organización de comidas colectivas, y las estrategias pautadas de búsqueda de apoyos entre los vecinos del área, entre las organizaciones políticas más sensibles al problema y entre la nutrida comunidad peruana del Abasto. El campamento se va afirmando como un núcleo de solidaridad vecinal, adonde no paran de llegar residentes de la zona que traen ropa vieja y mantas para las familias, mientras algunos de los muchos peruanos que regentan restaurantes en la zona acercan al final del día sopas y arroz. La calle Zelaya, en definitiva, es construida como un espacio de impugnación, que denuncia la injusticia derivada del modelo de urbanismo neoliberal; pero también como un conjunto de prácticas espaciales alternativas, que implican lógicas de carácter solidario y cooperativo.

Más allá de esta intervención física permanente sobre la calle Zelaya, los vecinos van a desplegar todo un conjunto de iniciativas orientadas a visibilizar y denunciar en otros espacios la situación que padecen. En esta tarea, la propia centralidad del barrio en el que viven les facilita el acceso a lugares de gran afluencia y alto valor simbólico. Espacios como el Shopping Abasto y la cortada Carlos Gardel, ubicados a apenas doscientos metros de la casa, van a ser escogidos como escenarios en los que hacer público su problema y señalar a los responsables de los mismos. Así, durante las tardes, es frecuente que grupos de vecinas se aposten a la entrada del centro comercial, o 
en la esquina de Carlos Gardel, portando la pancarta ya citada que preside la calle $\mathrm{y}$, al menos durante las primeras veces, repartiendo octavillas elaboradas con el apoyo del CIBA, Nuevo Encuentro y La Brecha. Entre quienes llevan a cabo estas protestas está muy presente la idea de que con un corto desplazamiento físico hasta estos lugares consiguen entrar en contacto con un perfil poblacional totalmente diferente al suyo, que no acostumbra a ver de cerca el drama de la vivienda de Buenos Aires y que no espera ser importunado en un paseo generalmente orientado a actividades recreativas. De esta forma, los mismos flujos de turistas y consumidores de clase media que el proceso de gentrificación ha dirigido al barrio son reconvertidos en escaparates a través de los que amplificar la incidencia de sus acciones de protesta. La ocupación de estos espacios y su uso para actividades no previstas -despliegue de pancartas, reparto de octavillas, coreo de cantos de protesta- ofrecen una eficacia añadida al desarrollarse en contacto directo con los turistas y consumidores acomodados que encarnan en primera persona el discurso gentrificador en el Abasto.

Podríamos decir que el objetivo principal de este tipo de iniciativas es, por expresarlo de un modo gráfico, generar interferencias en la imagen armónica del Abasto recualificado, y utilizar los propios referentes del proyecto gentrificador para amplificar el efecto del discurso de impugnación. Esta lógica de la interferencia, sin embargo, llega adquirir en ocasiones formas más contundentes. Merece la pena citar a este respecto la mayor movilización desarrollada por los vecinos a lo largo de su trayectoria de lucha. Nos referimos al corte de la avenida Corrientes, que se desarrolla el 29 de julio, apenas una semana después de producido el incendio.
El corte de Corrientes es decidido en asamblea por los vecinos, y cuenta con el apoyo de las organizaciones políticas Nuevo Encuentro y La Brecha, así como del CIBA y de la Asociación de Mujeres Unidas, Migrantes y Refugiadas en Argentina (AMUMRA), organización de migrantes liderada por un grupo muy activo de mujeres peruanas. Debe considerarse que la avenida Corrientes, ubicada a apenas dos cuadras de Zelaya hacia el Este, constituye una de las principales arterias de la ciudad, tanto por su importancia en la distribución del tráfico en la zona centro de la ciudad como por la actividad comercial y el valor simbólico que alberga. El corte se realiza además en el cruce con la avenida Agüero, donde se ubica la entrada al Shopping Abasto, y no por casualidad es programado para un viernes a media tarde, sin duda uno de los momentos de más tráfico en una zona ya de por sí muy transitada. El objetivo evidente es lograr el máximo impacto posible.

La avenida cuenta a esta altura con seis carriles de dirección única hacia el centro de la ciudad, que en el momento del corte se encuentran atestados de vehículos que traen a sus ocupantes de vuelta del trabajo o los llevan a divertirse tras una dura semana. Aprovechando un cierre del semáforo que rige el tráfico en el cruce, los seis carriles van a ser cortados por más de doscientas cincuenta personas que portan pancartas, reparten octavillas y generan un gran revuelo con dos megáfonos y un grupo de batucada solidario que acompaña con frecuencia este tipo de movilizaciones en la zona. Muy pronto varios policías llegan al cruce $\mathrm{y}$, sin generar confrontación alguna, se dedican diligentemente a reorientar el tráfico hacia las cuadras aledañas. Al ritmo de los tambores, y bajo la dirección de varias vecinas que agarran los megáfonos y se ubican al frente de la protesta, los congregados cantan incesantemente letras que 
abundan en el problema de la vivienda, en una de las esquinas más cotizadas de Buenos Aires y frente al edificio de un mercado que, reconvertido en Shopping, encarna en sus enormes vidrieras y en sus imponentes muros la potencia arrasadora del modelo de urbanismo neoliberal.

“Olé olé,

olé olá,

vivienda digna,

justicia ya,

en la calle no se puede vivir más".

Al cabo de una hora de corte, el cruce de Corrientes con Agüero se encuentra desierto, y desde el punto exacto en que las calles se cruzan es posible disfrutar de la inédita imagen vacía y silenciosa de una de las avenidas más conocidas del mundo. Una vez cumplido este objetivo, y garantizado el impacto mediático de la iniciativa, la ocupación del cruce se reconstruye en una improvisada manifestación que comienza a descender Corrientes a lo largo del lateral del Shopping, y otra cuadra más, hasta la calle Jean Jaures, donde doblamos a la izquierda para entrar en la cortada Carlos Gardel y recorrerla por entero. En este momento, y hasta nuestra llegada, la Carlos Gardel es un romántico escenario de farolitos y restaurantes que sacan a la calle sus mesas y sillas para los turistas y locales de mayor nivel adquisitivo. El recorrido de la manifestación por la calle marca una escena de máximo contraste entre los dos grandes procesos poblacionales que hoy caracterizan al Abasto: la llegada de los ricos y la expulsión de los pobres. Pero la estampa aún guarda una sorpresa: junto a esos mismos restaurantes, en otra casa chorizo donde los últimos vecinos pobres de la calle enfrentan una amenaza de desalojo, se representa ante los asistentes un encuentro fraternal entre dos grandes grupos de vecinos en lucha. A lo largo de más de media hora, vecinos de las casas de Gardel y de Zelaya, así como representantes del CIBA y hasta una comunera kirchnerista de la zona, intervienen para denunciar la especulación en la zona, reivindicar un blindaje del derecho a la vivienda frente a la avaricia de los inversores y repetir hasta la saciedad la importancia de estar unidos, de movilizarse y de no permitir que se les arrebate el barrio. Los turistas, mientras tanto, apuran sus platos de sopa y miran perplejos, tal vez preguntándose de dónde llegó tanto peruano.

\section{Reflexiones finales}

La moral neoliberal es la moral del mercado, la del respeto a la legalidad y la disciplina social de la propiedad privada. Como tal, forma parte de la naturalización ideológica del orden social que se viste con unos ropajes éticos y de sentido común. Por lo tanto, el acceso a la centralidad no es solamente negado por la violencia física (el incendio, el desalojo, el frío en la calle), que es estructural, sino también y muy relevantemente por una violencia simbólica que condena a las clases populares por acceder a espacios que les son vedados.

De esta forma las clases populares deben buscar sus propias formas de justificar y legitimar su posición ideológicamente. La idea de economía moral define bastante bien este discurso, y es posible identificar su dimensión espacial: la injusticia y la justicia espacial, la distribución y redistribución geográfica de habitantes y recursos, el acceso a los recursos que proporciona la ciudad y el centro urbano, el derecho a la vivienda, la 
supeditación del valor de cambio al valor de uso del espacio.

Ahora bien, si los discursos no son ajenos a las prácticas (Harvey, 1977), ¿Qué prácticas espaciales se asocian a este discurso ideológico? Como prácticas espaciales, el mercado y la propiedad son prácticas monopólicas, que imponen una concepción absoluta del espacio y una normativización que favorece su carácter de espacio de consumo. En conjunto niega sistemáticamente el acceso a la centralidad a las clases populares. El acceso a la ciudad viene dado por el puro poder del dinero, de poder pagar un alquiler, de poder pagar los servicios básicos, etcétera. En el lado opuesto encontramos precisamente la transgresión de la propiedad, del civismo y del monopolio del espacio. Junto a esto, relaciones de apoyo basadas en el parentesco o la nacionalidad (los primos y los hermanos, la interpelación en tanto que peruanos a ayudar) totalmente ajenas a la ética liberal del logro personal y formas de asociación comunitarias (cuidado de los niños, tareas domésticas, reparaciones del edificio, pago de servicios colectivos) que implican generalmente un uso intensivo de los espacios comunes del conventillo y de zonas comunes aledañas a la vivienda. Estas prácticas se dirigen a asegurar el acceso a la centralidad, asimilable en este caso prácticamente al derecho a la ciudad, que proporciona seguridad física, trabajo y acceso a dotaciones colectivas. La propia posibilidad de mejorar la vida pasa por acceder a la centralidad.

Frente a la exaltación común de la capacidad de acción de los pobres, de resistencia ideológica y de la capacidad de desobedecer las normas del orden establecido podemos hacer no obstante varias objeciones que emanan directamente de la lectura del caso.
En primer lugar, sería ingenuo pensar que los recursos discursivos que las clases populares utilizan para legitimar la ruptura de un orden legal son ajenos a la ideología dominante. El acto de desobediencia debe legitimarse ante una sociedad donde este acto está proscrito. Podríamos decir que los valores morales de este discurso no son necesariamente ajenos a la ideología dominante, sino que encuentran hueco dentro de la misma y por ello tiene efectividad. La sanción negativa de la acaparación, los recursos ociosos (casas vacías) y otros elementos del discurso de los ocupantes son parte también de cierta moral generalizada, al mismo tiempo que ajenos a la legitimidad puramente liberal del mercado. No hay moral o ética más allá de la ideología. Como señala Zizek (2011), la ideología dominante siempre implica un fondo de reivindicaciones justas $\mathrm{y}$ verdaderas de las clases dominadas, que aseguran su propia efectividad.

En segundo lugar, trasladando esto a las prácticas espaciales, observamos que la plasmación en la práctica del acceso a la centralidad, entendido como derecho colectivo, excede la capacidad de acción de las resistencias cotidianas de los pobres. Ninguna acción grupal garantiza un cambio en las formas de acceso a la ciudad y la centralidad si no persigue cambios en la forma en que se distribuye y asigna el espacio, es decir, si no actúa sobre el mercado de suelo y sobre la legalidad sobre la que se sostiene.

Más allá incluso de lo anterior, la propia configuración de una ciudad como Buenos Aires, fuertemente centralizada, implica ya inevitablemente una negación del acceso a la ciudad para la mayor parte de la población. Los pequeños procesos de reordenación que suponen los actos de desobediencia parecen en este sentido impotentes ante las capas históricas de ordenación, recursos y símbolos que 
conforman la ciudad. Una realización efectiva de la justicia socio-espacial en los términos morales de igualdad, de distribución de recursos, implicaría siempre una reordenación a gran escala de la propia ciudad.

La lucha se transforma en política cuando adquiere la forma de una protesta pública, cuando interpela a actores políticos, cuando se encuentra con otros con similares problemas, cuando busca incidir sobre la opinión pública, esto es, cuando los ocupantes toman el espacio público y no antes. La diferencia entre una protesta política y una desobediencia orientada a la propia supervivencia es que la primera busca algún tipo de transformación del orden espacial mientras que la segunda implica algún tipo de adaptación espuria a los órdenes existentes. La ocupación puede ser una resistencia cotidiana, una forma de supervivencia atravesando la legalidad y las normas de organización y uso del espacio. Sin embargo, cuando la cuestión salta al espacio público se abre la posibilidad de vincularse a procesos de reordenación del espacio social, se abre la oportunidad para la política. La ocupación de la calle como protesta transforma a ambos, calle $y$ conventillo, en espacios políticos.

\section{BIBLIOGRAFA}

Carman, María (2006), Las trampas de la cultura. Los intrusos y los nuevos usos del barrio de Gardel. Buenos Aires, Paidos.

Díaz Parra, Ibán (2014), "El regreso a la ciudad consolidada", Ciudades. Análisis de coyuntura, teoría e historia urbana, núm. 103.

Diaz Parra, Iban (2016), "Las Manos sobre la ciudad. Carlos Slim y George Soros como agentes de la gentrificción”, El canelazo de la ciudad, núm. 5, pp. 66-78

Harvey, David (1977), Urbanismo y justicia social. Madrid, Siglo XXI.

Harvey, David (1996), Justice, Nature and the Geography of Difference. Oxford, Wiley-Blackwell.

Harvey, David (2013), Ciudades rebeldes. Madrid, Akal.

Holloway, John (2011), Agrietar el capitalismo. El hacer contra el trabajo.

Buenos Aires, Ediciones Herramienta.
Larraín, Jorge (2007), Ideología. Carlos Marx. Vol. 1. Santiago de Chile, LOM.

Lefebvre, Henri (1968), El derecho a la ciudad. Barcelona, Ediciones península.

Lefebvre, Henri (1973), Espacio y política. Barcelona, Ediciones península.

Lefebvre, Henri. 2013. La producción del espacio. Madrid: Capitan Swing.

Roca, Beltrán (2017), "Pensar con James Scott: Dominacion, conocimiento, resistencia”, Araucaria. Revista Iberoamericna de Filosofía, Política y Humanidades, vol. 19, núm. 37, pp. 91-113.

Rodríguez, María Carla (2009), "Derecho a la ciudad y autogestión cooperativa en Buenos Aires", Centro- $h$, núm 3, abril.

Thompson, Edward Palmer (2012), La formación de la clase obrera en Inglaterra. Madrid, Capitan Swing.

Scott, James C. (2003), Los dominados y el arte de la resistencia. Tafalla, Txalaparta.

Zizek, Slavoj (2008), Primero como tragedia, después como farsa. Madrid, Akal.

Zizek, Slavoj (2011), El espinoso sujeto. El centro ausente de la ontología política. Buenos Aires, Paid 
